\title{
1,1-Difluoro-1-alkenes as New Electrolyte Additives for Lithium Ion Batteries
}

\author{
Tadahiko Kubota $^{\text {a*}}$, Masayuki Ihara ${ }^{\mathrm{a}}$, Shinichi Katayama ${ }^{\mathrm{b}}$, Hideki Nakai ${ }^{\mathrm{b}}$, Junji Ichikawa ${ }^{\mathrm{c}}$ \\ ${ }^{\mathrm{a}}$ Sony Corporation, ${ }^{\mathrm{b}}$ Sony Energy Devices Corporation \\ 1-1 Aza, Shimosugishita, Takakura, Hiwada-machi, Koriyama-shi, Fukushima 963-0531, Japan \\ ${ }^{\mathrm{c}}$ Department of Chemistry, Graduate School of Pure and Applied Sciences, \\ University of Tsukuba, Tsukuba, Ibaraki 305-8571, Japan
}

\footnotetext{
*Corresponding author. Tel: +81249586791 ; fax: +81249582077.

E-mail address: Tadahiko.Kubota@jp.sony.com
}

\begin{abstract}
Five 1,1-difluoro-1-alkenes bearing aryl groups are investigated as electrolyte additives for high charge voltage lithium ion batteries with an aim to induce favorable solid electrolyte interphase (SEI) formation. Among them, 1,1-difluoro-4-phenylbut-1-ene (DF-1) forms appropriate SEIs on the cathode and anode by its reactions under oxidative and reductive conditions, respectively, which was suggested by linear sweep and cyclic voltammetry. The SEIs formed with the DF-1 containing electrolyte on the cathode and anode were analyzed by X-ray photoelectron spectroscopy and time of flight-secondary ion mass spectrometry, indicating the following: (i) the cathode surface has a LiF-rich layer with unsaturated hydrocarbons, and (ii) the anode surface also has a LiF-rich layer, which probably includes fluoromethylene (CHF) compounds. The formation of the SEIs on both electrodes with DF-1 results in low impedance being maintained, and thus, particularly good cycle performance even at high charge voltage.
\end{abstract}

Keywords: lithium ion battery, electrolyte additive, 1,1-difluoro-1-alkene, solid electrolyte interphase, XPS, ToF-SIMS 


\section{Introduction}

Since Sony commercialized the first lithium ion battery in 1991, there has been an increase in the application of mobile devices, such as laptop PCs, cellular phones, and digital cameras. In recent years, lithium ion batteries have gained increasing attention as an important device for electric vehicles and power storage systems. Lithium ion batteries for these applications are expected to have high performance, such as high energy density, high stability, rapid charge performance, and low cost. High energy density is one of particularly strong requirements. Therefore, active cathode and anode materials have been developed for this purpose [1,2]. To improve the cycle performance of these high capacity lithium ion batteries, solid electrolyte interphase (SEI) is highly effective to prevent decomposition of electrolytes, so that numerous studies have been conducted with respect to SEI. Electrolyte additives, such as vinylene carbonate (VC) and ethylene sulfite (ES) are well known as favorable SEI-forming materials to improve cycle performance [3,4].

Recently, fluorine-containing electrolyte additives, such as methyl difluoroacetate and fluoroethylene carbonate (FEC), have been developed to form a stable SEI [5,6]. The composition of FEC-derived SEI on silicon anode was investigated in detail [7], which revealed that the SEI consisted of lithium fluoride and polyene compounds. Both of them are insoluble in electrolyte solvents and keep the SEI effective.

Whereas several additives work effectively for improvement of cycle performance because of SEI formation on anodes, additives for cathode SEI have been paid much less attention. For conventional lithium ion batteries, their charge voltages are controlled by chargers to keep under $4.20 \mathrm{~V}$. Under this condition, electrolytes are relatively stable on cathode side. However, in these days charging voltage is getting higher to get high energy density, in which situation SEI on cathodes become important for preventing decomposition of electrolytes. Whereas there have been studies to develop new electrolyte additives for cathodes $[8,9,10,11]$, they are still not enough to fulfill the requirement.

Ichikawa and coworkers reported that 1,1-difluoro-1-alkenes bearing an aryl group underwent a Friedel-Crafts-type cyclization with a loss of HF $[12,13]$ as shown in Scheme 1. This inspired us to use them as electrolyte additives in lithium ion batteries, because strongly acidic and oxidative 
atmosphere around the charged cathode seemed to induce reactions similar to the above cyclization. As a result, the generated $\mathrm{HF}$ would afford $\mathrm{LiF}$ in the batteries, and the aromatic parts of difluoroalkenes could be polymerized. Thus, we envisioned that these insoluble products containing LiF could act as effective SEIs on cathodes.<smiles>C=C(F)CCc1ccccc1</smiles>

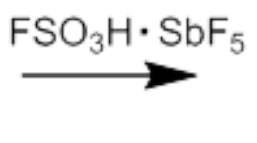<smiles>FC1(F)CCCc2ccccc21</smiles><smiles>C[PH-]C</smiles><smiles>F[C+]1CCCc2ccccc21</smiles><smiles>O=C1CCCc2ccc(F)cc21</smiles>

Scheme 1. Friedel-Crafts-type cyclization of 1,1-difluoro-1-alkenes

In this paper, we report that one of 1,1-difluoro-1-alkenes examined exerts beneficial effects on cycle performance of high voltage lithium ion batteries and that the formed SEIs were investigated by X-ray photoelectron spectroscopy (XPS) and time of flight-secondary ion mass spectrometry (ToF-SIMS) to elucidate the effects of difluoroalkenes.

\section{Experimental}

\subsection{Synthesis of 1,1-difluoro-1-alkenes}

Five difluoroalkenes bearing one or two aryl groups were synthesized and their structures are presented in Figure 1.<smiles>COc1ccc(CC/C=C\F)cc1</smiles>

DF-1

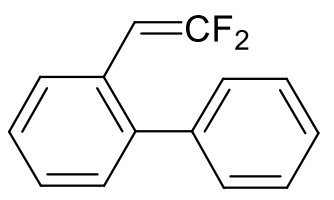

DF-3

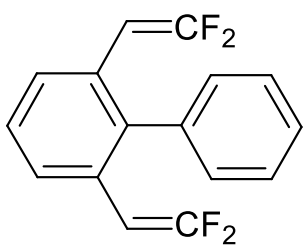

DF-4

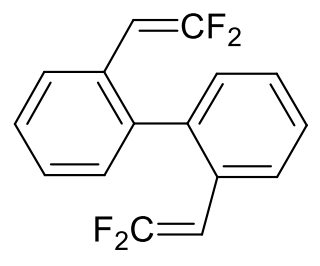

DF-5

Figure 1. Structures of 1,1-difluoro-1-alkenes examined

1,1-Difluoro-4-phenylbut-1-ene (DF-1) and 1,1-Difluoro-4-(4-methoxyphenyl)but-1-ene (DF-2) were 
prepared by a one-pot synthesis developed by Ichikawa et al. [12,13]. 2-(2,2-Difluorovinyl)biphenyl (DF-3), 2,2'-bis(2,2-difluorovinyl)biphenyl (DF-4), and 2,6-bis(2,2-difluorovinyl)biphenyl (DF-5) were prepared via difluoromethylenation of the corresponding aldehydes [14].

\subsection{Electrolyte preparation}

$\mathrm{LiPF}_{6}(1 \mathrm{~mol} / \mathrm{L})$ in a mixture of ethylene carbonate (EC) and dimethyl carbonate (DMC) (1:1 v/v) was employed as an electrolyte, and the difluoroalkene additives were added at $0.15 \mathrm{~mol} / \mathrm{kg}$ for $\mathrm{DF}-1,-2,-3$ and $\mathrm{PhB}, 0.075 \mathrm{~mol} / \mathrm{kg}$ for DF-4 and -5 . To confirm the effect of fluorine, a fluorine-free counterpart of DF-1, 4-phenyl-1-butene (PhB) were employed. The purity of each additive was confirmed by ${ }^{1} \mathrm{H}-\mathrm{NMR}$. No impurities were detected. The water content of each test solution was less than $20 \mathrm{ppm}$ as determined by Karl-Fischer titration method.

\subsection{Cell preparation}

\subsubsection{Cathode preparation}

The cathode material for the battery charge-discharge tests and X-ray photoelectron spectroscopy (XPS) measurements was prepared as follows. $\mathrm{LiCoO}_{2}$, graphite powder, and polyvinylidene fluoride were mixed in a weight ratio of 91:6:3. The cathode mixture was dispersed in $N$-methyl-2-pyrrolidone as a solvent to obtain a cathode slurry. A strip of $20 \mu \mathrm{m}$ thick aluminum foil was used as a cathode current collector and was uniformly coated with the cathode mixture slurry, dried, and then compress-molded with a rolling press machine to form the active cathode layer. The thickness of cathode was $68 \mu \mathrm{m}$ for $4.2 \mathrm{~V}$ charge, $58 \mu \mathrm{m}$ for $4.45 \mathrm{~V}$ and $4.50 \mathrm{~V}$ charge. The density and the energy density of cathode were $3.8 \mathrm{mg} / \mathrm{cm}^{3}$ and $4.5 \mathrm{mAh} / \mathrm{cm}^{2}$, respectively.

The cathode for XPS and ToF-SIMS measurements was prepared by sputter-depositing $\mathrm{LiCoO}_{2}$ to a thickness of $270 \mathrm{~nm}$ on a gold substrate $(100 \mu \mathrm{m}$ thick $)$ and sintering at $700{ }^{\circ} \mathrm{C}$ for $10 \mathrm{~h}$.

\subsubsection{Anode preparation}


For preparation of the graphite anode, graphite powder, styrene-butadiene rubber, and carboxymethyl cellulose were mixed in a weight ratio of $96: 2: 2$. The anode mixture was dispersed in water to obtain an anode slurry. The anode mixture slurry was uniformly applied on a $15 \mu \mathrm{m}$-thick anode copper foil current collector, dried, and compression-molded using a rolling press machine to form the active anode layer. The thickness of anode was $62 \mu \mathrm{m}$. The density and the energy density of anode were $1.8 \mathrm{mg} / \mathrm{cm}^{3}$ and $4.5 \mathrm{mAh} / \mathrm{cm}^{2}$, respectively.

\subsubsection{Cell assembly}

Cells were assembled using 2016 coin type cells (20 mm diameter, $1.6 \mathrm{~mm}$ thick) in a dry room with polyethylene separators.

\subsection{Electrochemical measurements}

\subsubsection{Linear sweep voltammetry (LSV) and cyclic voltammetry $(C V)$}

LSV and CV measurements of the coin cells were conducted using a Solartron 1287A potentiostat/galvanostat system. For oxidation side of coin cells, the above mentioned $\mathrm{LiCoO}_{2}$ electrode and Li metal foil were used as electrodes. For reduction side of coin cells, the above mentioned graphite electrode and Li metal foil were used as electrodes.

LSV was performed with cathodic scans from 3.0 to $7.0 \mathrm{~V}$ (vs. Li) using a Pt working electrode and $\mathrm{Li}$ as the reference electrode at a scan rate of $10 \mathrm{mV} / \mathrm{s}$ by using coin cells for oxidation side, and with anodic scans from the open circuit voltage $(\mathrm{OCV})$ to $0 \mathrm{~V}(\mathrm{vs}$. Li) at a scan rate of $0.1 \mathrm{mV} / \mathrm{s}$ by using coin cells for reduction side.

CV was measured from OCV to $5.5 \mathrm{~V}$ (vs. Li) using a Pt working electrode and Li reference electrode at scan rate of $10 \mathrm{mV} / \mathrm{s}$ with coin cells for oxidation side.

\subsubsection{Charge-discharge tests}

The cells were tested using a battery tester (TOSCAT 3100, Toyo System Co., Ltd.) at $25{ }^{\circ} \mathrm{C}$. The lithium anode half cell was charged to $4.20 \mathrm{~V}$ or $4.50 \mathrm{~V}$ at constant current-constant voltage of 0.2 
$\mathrm{mA} / \mathrm{cm}^{2}$, and discharge was performed at a constant current of $0.2 \mathrm{~mA} / \mathrm{cm}^{2}$ to $3.0 \mathrm{~V}$. The sputterdepositing cathode lithium half cell was charged to $4.50 \mathrm{~V}$ at a constant current-constant voltage of $0.05 \mathrm{~mA} / \mathrm{cm}^{2}$. The $\mathrm{LiCoO}_{2} /$ graphite cell was charged to $4.20 \mathrm{~V}$ or $4.45 \mathrm{~V}$ at a constant currentconstant voltage of $0.2 \mathrm{~mA} / \mathrm{cm}^{2}$, and discharged at a constant current of $0.2 \mathrm{~mA} / \mathrm{cm}^{2}$ to $3.0 \mathrm{~V}$.

\subsubsection{Impedance measurement}

Impedance was measured using a Solartron 1260 impedance analyzer. Frequency range and voltage amplitude were set as $1 \mathrm{MHz}$ to $0.1 \mathrm{~Hz}$ and $10 \mathrm{mV}$, respectively.

\subsection{Characterization}

Electrodes were removed from the cells in an Ar-filled glove box after the charge-discharge tests, washed with dimethyl carbonate (DMC) and then transferred for analysis using a sealed transfer vessel to avoid exposure to the air.

\subsubsection{XPS}

XPS measurements were performed using a spectrophotometer (Quantera SXM, Ulvac-Phi, Inc.) with monochromatized $\mathrm{Al} \mathrm{K} \alpha$ radiation $(1486.6 \mathrm{eV})$ and a $100 \mu \mathrm{m}$ diameter analysis area. Charge compensation for the sample was not applied during measurements to avoid damage to the surface structure, and the pressure in the analysis chamber was kept below $1.0 \times 10^{-6} \mathrm{~Pa}$. The binding energy of all acquired spectra was corrected to the F 1s peak at $685.1 \mathrm{eV}$ for LiF. Sputtering was conducted under conditions of $1 \mathrm{keV} \mathrm{Ar}+$ in a $1 \times 1 \mathrm{~mm}^{2}$ area for depth profiling of the SEI.

\subsubsection{ToF-SIMS}

ToF-SIMS measurements were performed using a spectrometer (TOF-SIMS5, ION-TOF GmbH) with a $25 \mathrm{keV} \mathrm{Bi}{ }^{3+}$ primary ion beam at a dose density of $9.8 \times 10^{11}$ ions $/ \mathrm{cm}^{2}$ and an analysis area of $200 \times 200 \mu \mathrm{m}^{2}$. Charge compensation for the sample was not applied during the measurements to avoid damage of the surface structure, and the pressure in the chamber was maintained below $1.0 \times 10^{-6} \mathrm{~Pa}$. 


\section{Result and discussion}

\subsection{Linear sweep voltammetry}

Figure 2 shows oxidation side LSV curves for electrolytes with DF-1 to DF-5 and 4-phenyl-1-butene $(\mathrm{PhB})$ additives, and without additive. For the electrolyte without additive there are no peaks until 6 V, which shows that this method is adequate to compare the effect of electrolyte additives until $6 \mathrm{~V}$. DF-2 has the lowest oxidation voltage. DF-3, -4 , and -5 have larger oxidation currents and lower oxidation voltages than $\mathrm{DF}-1$ and $\mathrm{PhB}$. PhB decomposes over 5.2 V, which suggests that $\mathrm{PhB}$ would be polymerized over $5.2 \mathrm{~V}$ (vs. Li). This kind of polymerizations are known for alkylbenzenes over $4.8 \mathrm{~V}$ (vs. Li) [15].

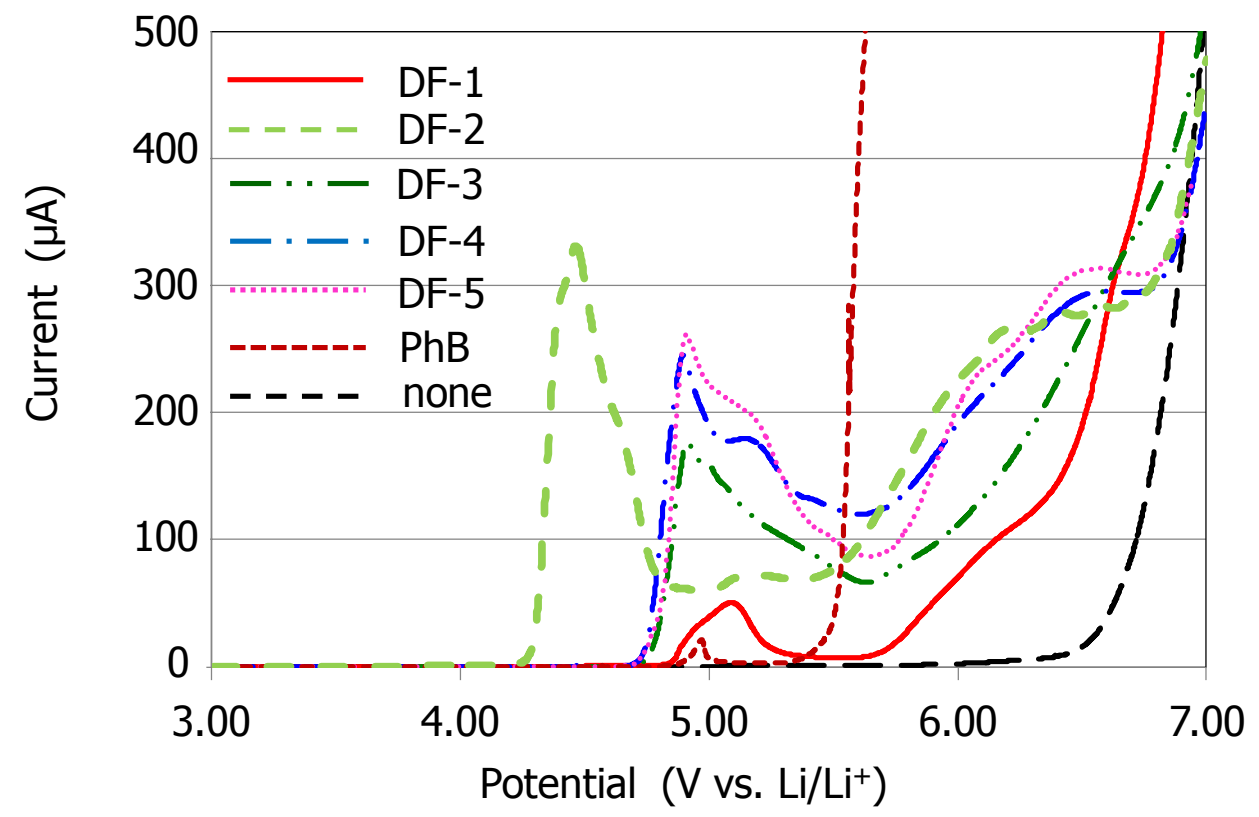

Figure 2. LSV for cells with electrolyte additives of DF-1 (red), DF-2 (yellow-green), DF-3 (green), DF-4 (blue), DF-5 (pink), PhB (brown), and without additive (black).

Figure 3(a) shows reduction side LSV curves for electrolytes with DF-1 to DF-5, PhB, and without additive. DF-2, $-3,-4$, and -5 have larger reduction currents and higher reduction voltages than DF-1 and $\mathrm{PhB}$. Figure 3(b) shows that DF-1 has a small reduction peak at $0.95 \mathrm{~V}$. The peak at $0.65 \mathrm{~V}$ is due to the reaction of the electrolyte solvent with the graphite anode [16]. 
The oxidation and reduction peaks in the LSV curves suggest SEI forming abilities of the additives examined. DF-1 in particular has the abilities on both sides, but they are much smaller than those of others, which would lead to appropriate SEI formation (vide infra).
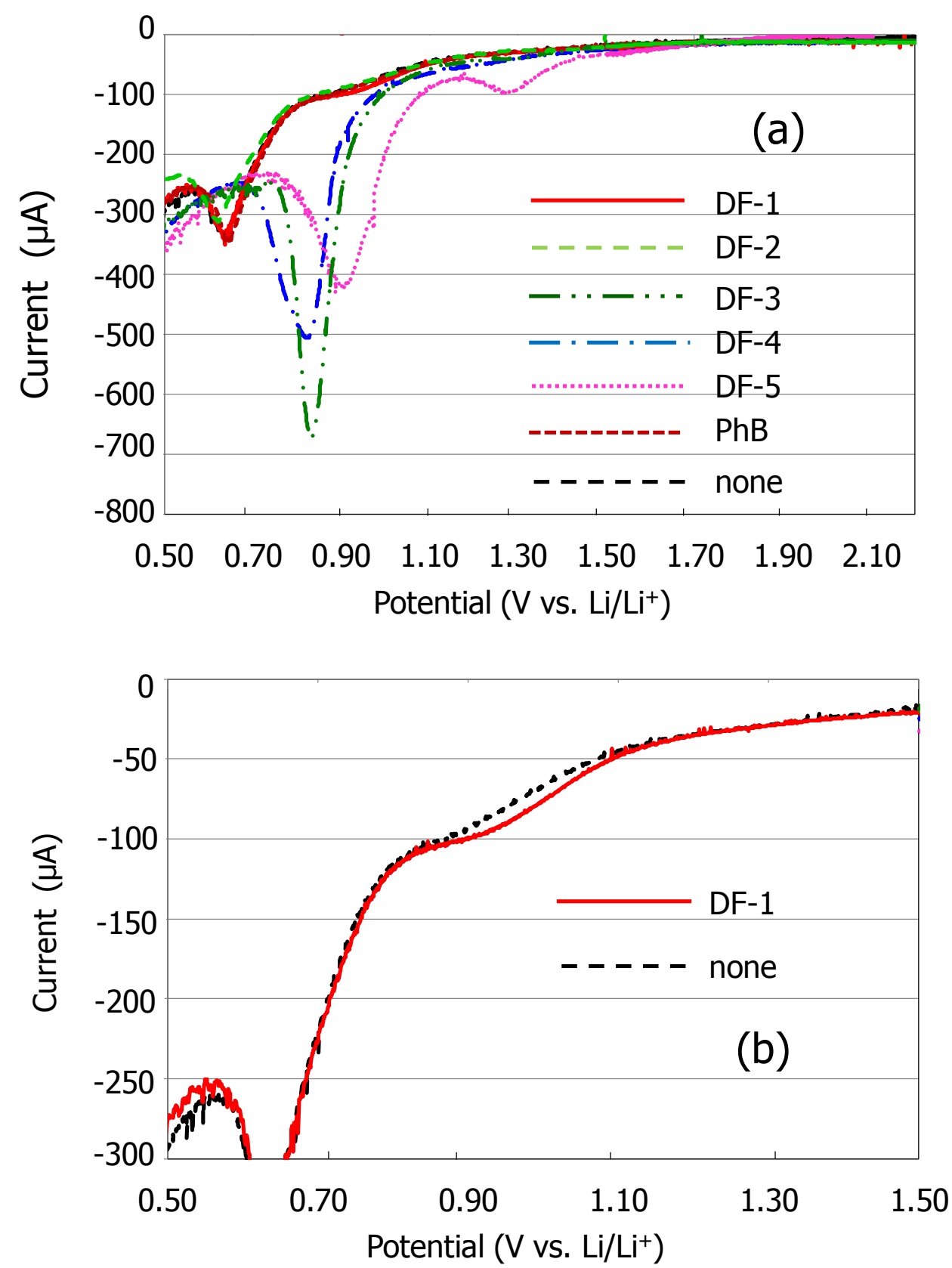

Figure 3. (a) LSV for cells with electrolyte additives of DF-1 (red), DF-2 (yellow-green), DF-3 (green), DF-4 (blue), DF-5 (pink), PhB (brown), and without additive (black). (b) Enlarged part of (a) with DF-1 (red) and without additive (black). 


\subsection{Cyclic voltammetry}

Cyclic voltammograms for electrolytes with DF-1 to DF-5, PhB, and without additive from 4.0 to 5.5 $\mathrm{V}$ are shown in Figures 4 (a) to (g). Peaks are not reversible and they become smaller during three cycles. In this range the electrolytes with $\mathrm{PhB}(\mathrm{f})$ and without additive (g) show no oxidation peaks. The electrolytes with DF-2, $-3,-4$, and $-5[(\mathrm{~b})-(\mathrm{e})]$ show oxidation peaks even at the second and third cycles, while DF-1 (a) shows an oxidation peak only at the first cycle. DF-1 probably forms a passivation film under oxidative condition.
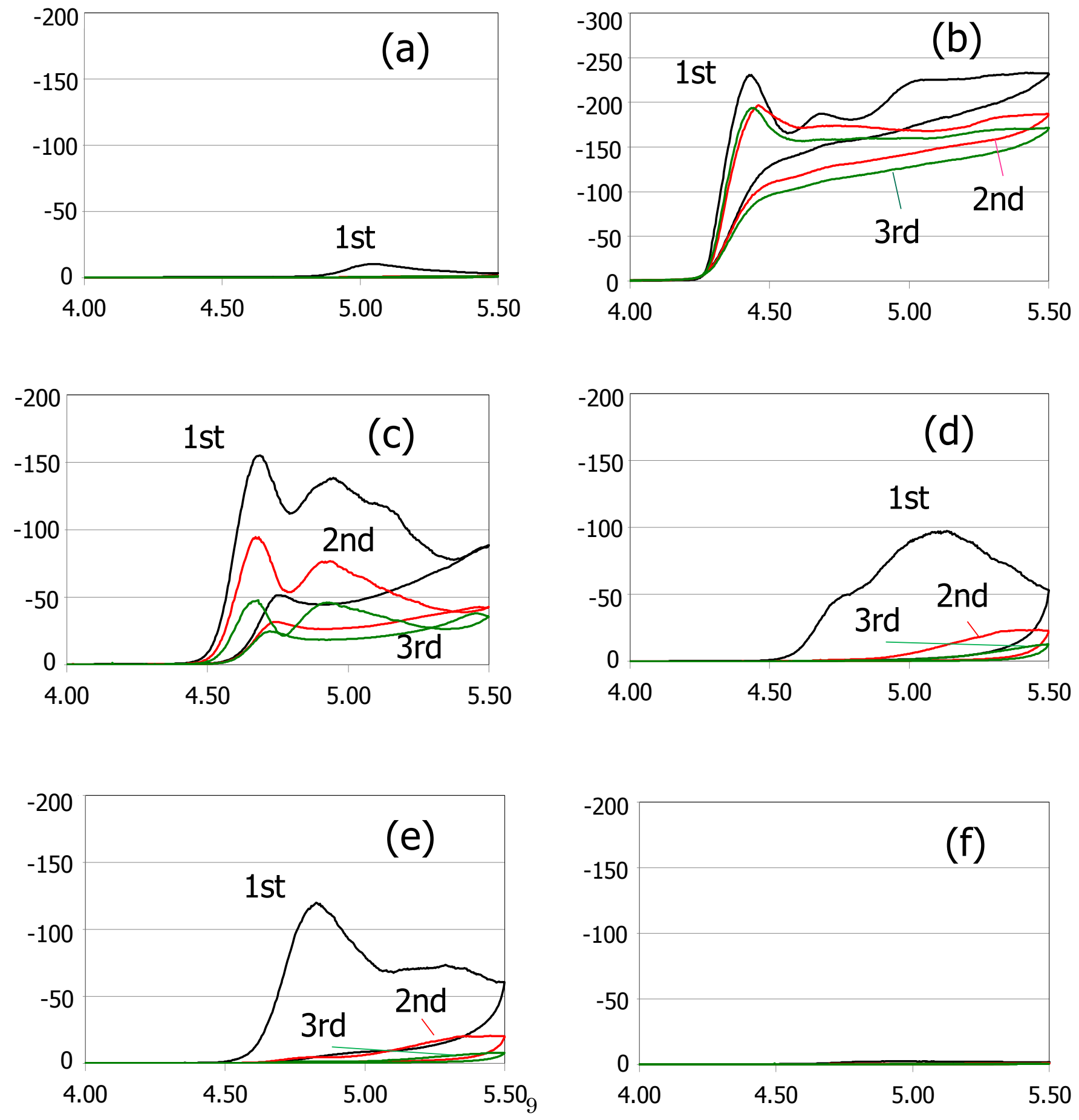


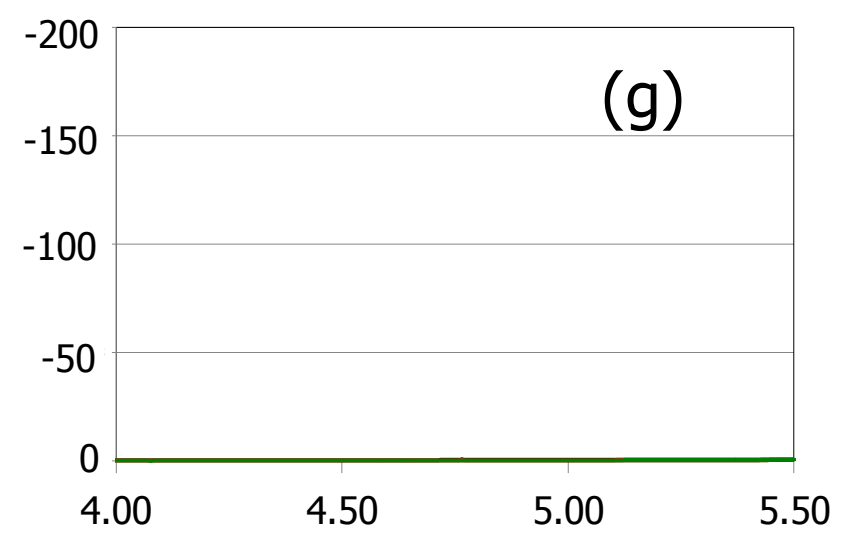

Figure 4. Cyclic voltammograms for cells with electrolyte additives of (a) DF-1, (b) DF-2, (c) DF-3, (d) DF-4, (e) DF-5, (f) PhB, and (g) without additive. The 1st, 2nd, and 3rd cycles are presented in black, red, and green, respectively.

\subsection{Charge voltage efficiency and anode material dependency}

Figures 5 and 6 show the charge voltage efficiency for the first cycle with electrolyte additives of DF-1 to $-5, \mathrm{PhB}$, and without additive, using lithium and graphite anodes, respectively. For lithium anodes, the additives do not affect the efficiency at $4.2 \mathrm{~V}$ charge. However, at $4.5 \mathrm{~V}$ charge, DF-2, $-3,-4$, -5 , and $\mathrm{PhB}$ result in low efficiency, because they react with the cathode over $4.20 \mathrm{~V}$. For graphite anodes, DF-1 to -5 show low efficiency compared to the electrolyte without additive. It suggests that DF-1 to -5 react with graphite. At $4.50 \mathrm{~V}$ charge, $\mathrm{DF}-2,-3,-4,-5$, and $\mathrm{PhB}$ additives also result in low efficiency, while DF-1 keeps an efficiency similar to that of the electrolytes without additive.

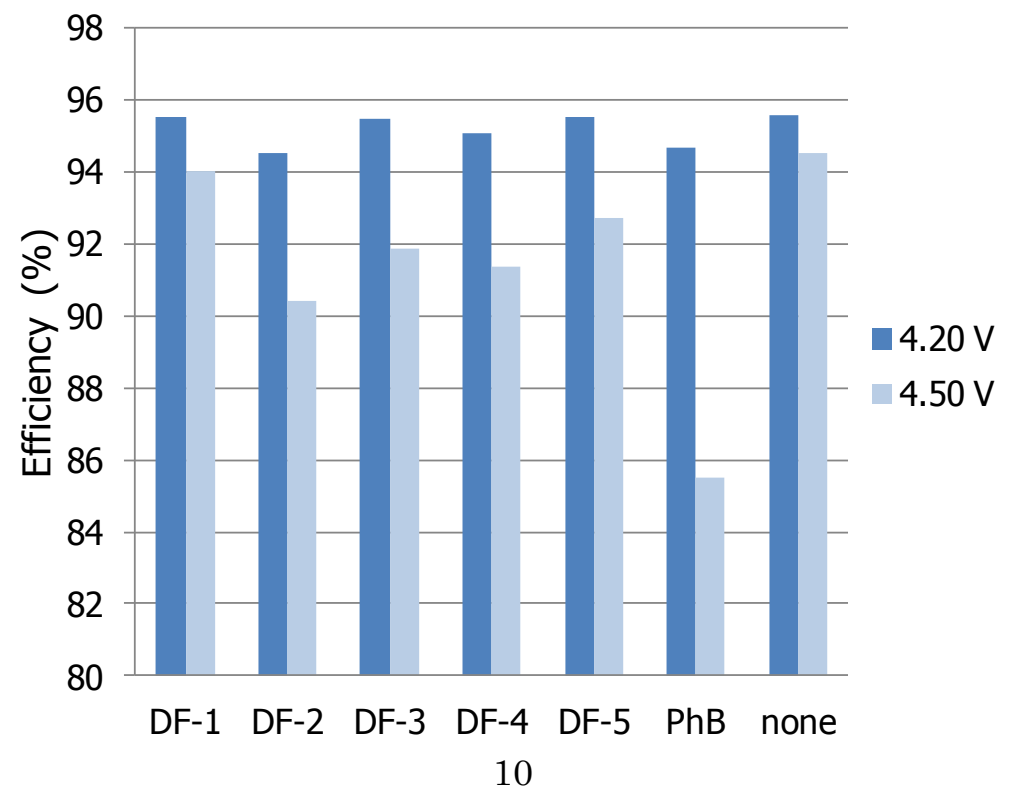


Figure 5. 1st cycle efficiency for cells with electrolyte additives and without additive using lithium anodes. The charge-discharge voltages are $4.20-3.0 \mathrm{~V}$ and $4.50-3.0 \mathrm{~V}$.

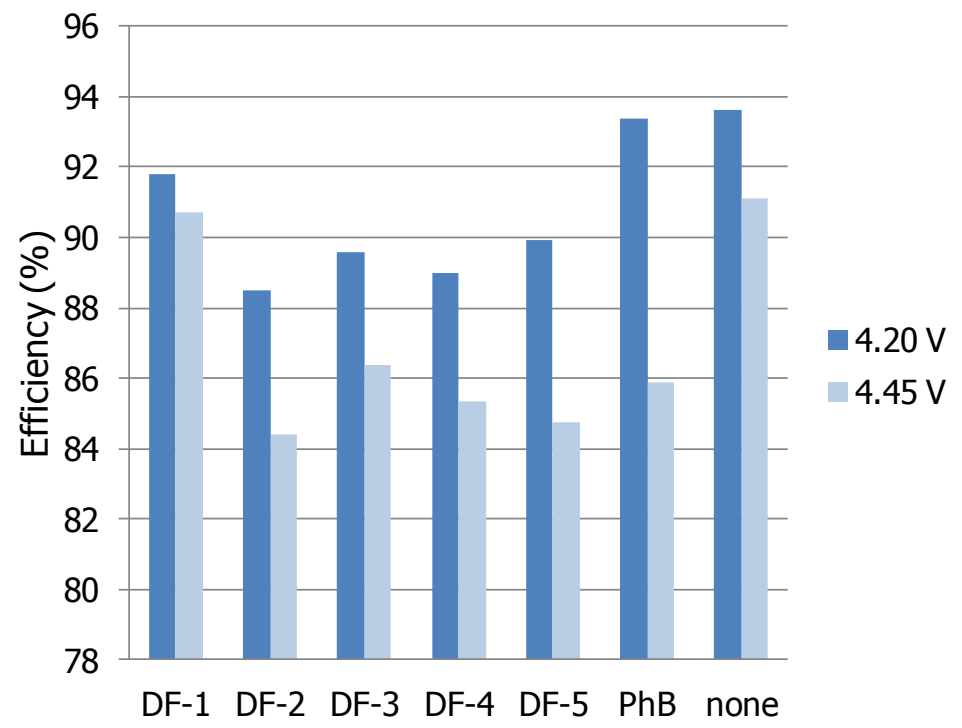

Figure 6. 1st cycle efficiency for cells with electrolyte additives and without additives using graphite anode. The charge - discharge voltages are $4.20-3.0 \mathrm{~V}$ and $4.45-3.0 \mathrm{~V}$.

For graphite anodes, the DF-2 to -5 electrolyte additives result in low efficiency even at $4.20 \mathrm{~V}$ charge, which is consistent with the LSV results presented in Figure 3, because DF-3 to -5 easily react with graphite. At $4.45 \mathrm{~V}$ charge, $\mathrm{DF}-2$ to -5 and $\mathrm{PhB}$ show a significant decrease in efficiency, as observed for lithium anodes. DF-1 again keeps an efficiency similar to that of the electrolyte without additive as shown in Figure 6.

\subsection{Cycle performance and change in impedance}

The cycle performance at 4.20 and $4.45 \mathrm{~V}$ charge is tested using the $\mathrm{LiCoO}_{2} /$ graphite cell. Figure 7 shows the results for charge at $4.20 \mathrm{~V}$, where the DF- 1 to -5 electrolytes have almost the same cycle performance as that for the electrolyte without additive. The $\mathrm{PhB}$ additive results in low cycle performance and a large increase in impedance, as evident from the Cole-Cole plot shown in Figure $8(b)$.

At $4.20 \mathrm{~V}$ charge, the DF-1 to -5 electrolytes exhibit almost the same cyclability as that of the control electrolyte without additive. The cell with the $\mathrm{PhB}$ additive exhibits the lowest cyclability. 

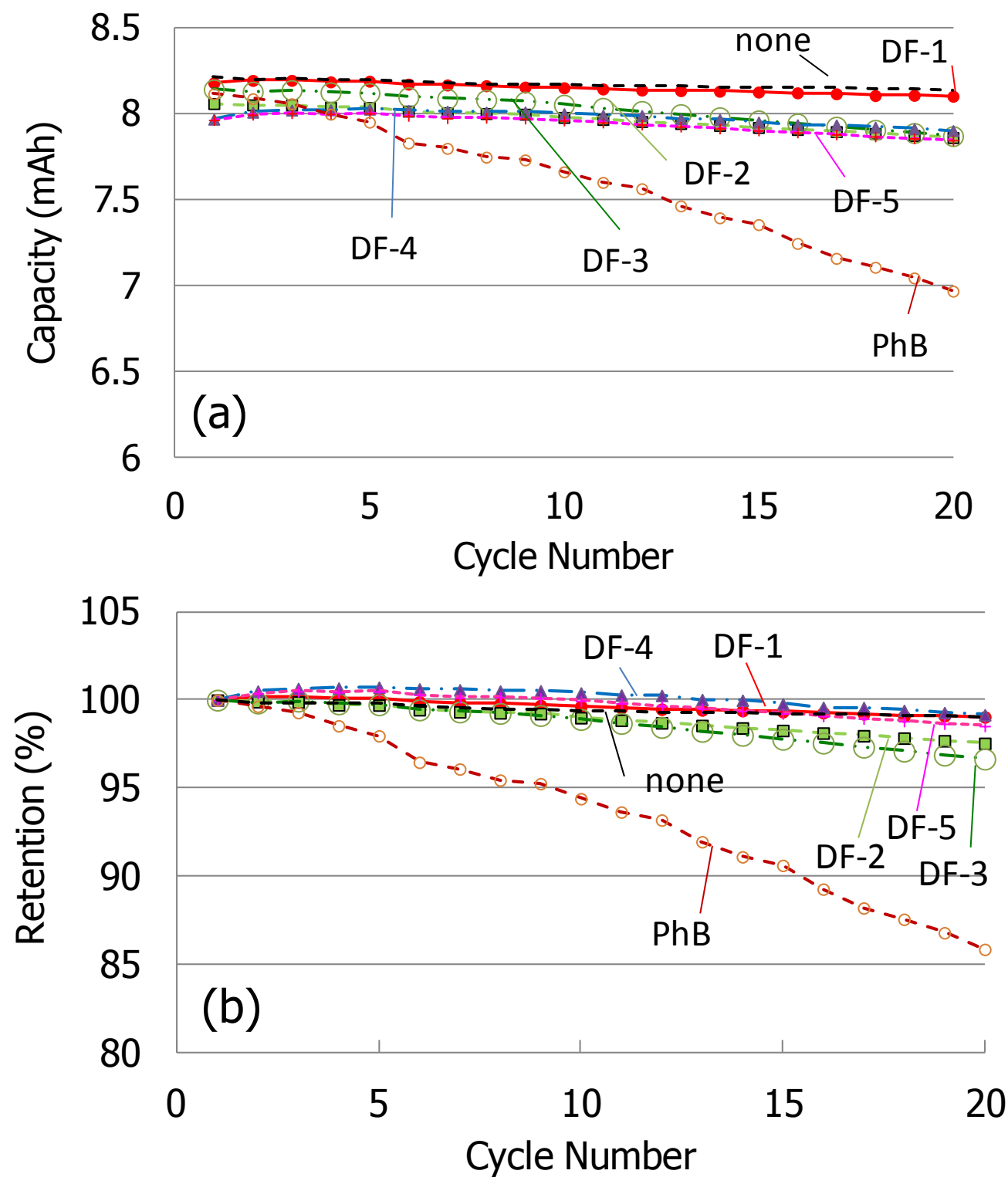

Figure 7. Cycle tests for $\mathrm{LiCoO}_{2} /$ graphite cells cycled between $4.20-3.0 \mathrm{~V}$ : (a) capacity and (b) retention for cells with electrolyte additives of DF-1 (red), DF-2 (yellow-green), DF-3 (green), DF-4 (blue), DF-5 (pink), PhB (brown), and without additive (black).

Figure 8 shows the change in impedance from the first to twentieth cycles. After the first cycle, the electrolytes with $\mathrm{DF}-1,-2, \mathrm{PhB}$, and without additive have almost the same impedance, which is smaller than those for the electrolytes with DF-3, -4, and -5. After the twentieth cycle the impedance of all samples increase, and that for $\mathrm{PhB}$ increases significantly.

The results of cycle test for charge at a higher voltage, $4.45 \mathrm{~V}$ are shown in Figure 9. DF-1 exhibits the best cycle performance among the examined electrolytes with and without additives. 

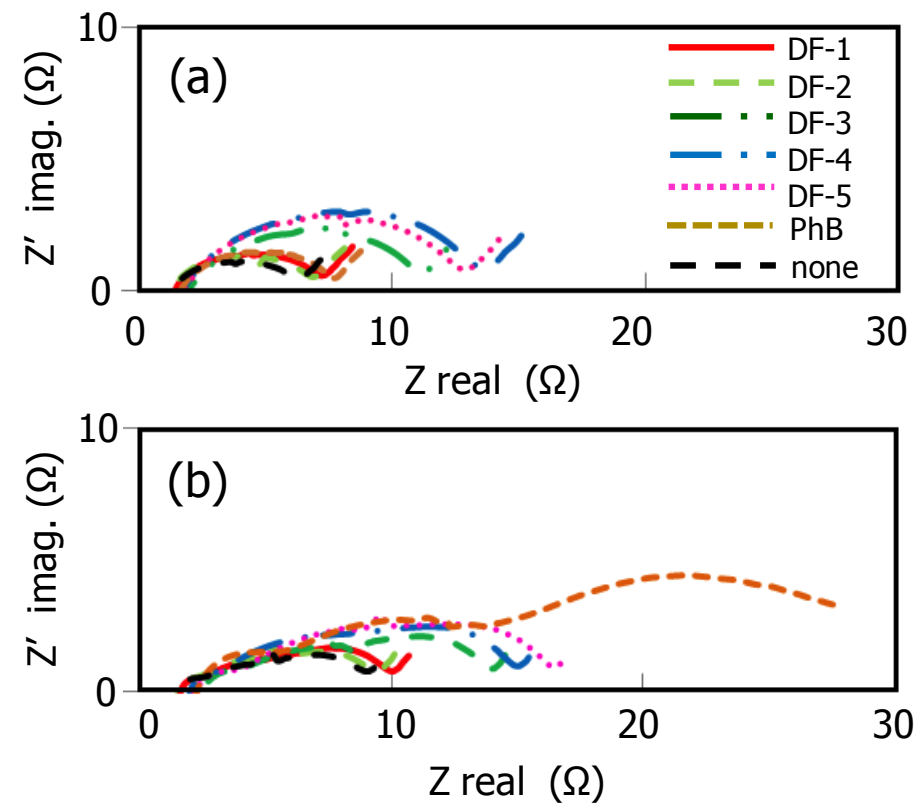

Figure 8. Cole-Cole plots for $\mathrm{LiCoO}_{2} /$ graphite cells cycled between $4.20-3.0 \mathrm{~V}$ at the (a) 1 st and (b) 20th cycles with electrolyte additives of DF-1 (red), DF-2 (yellow-green), DF-3 (green), DF-4 (blue), DF-5 (pink), PhB (brown), and without additive (black).
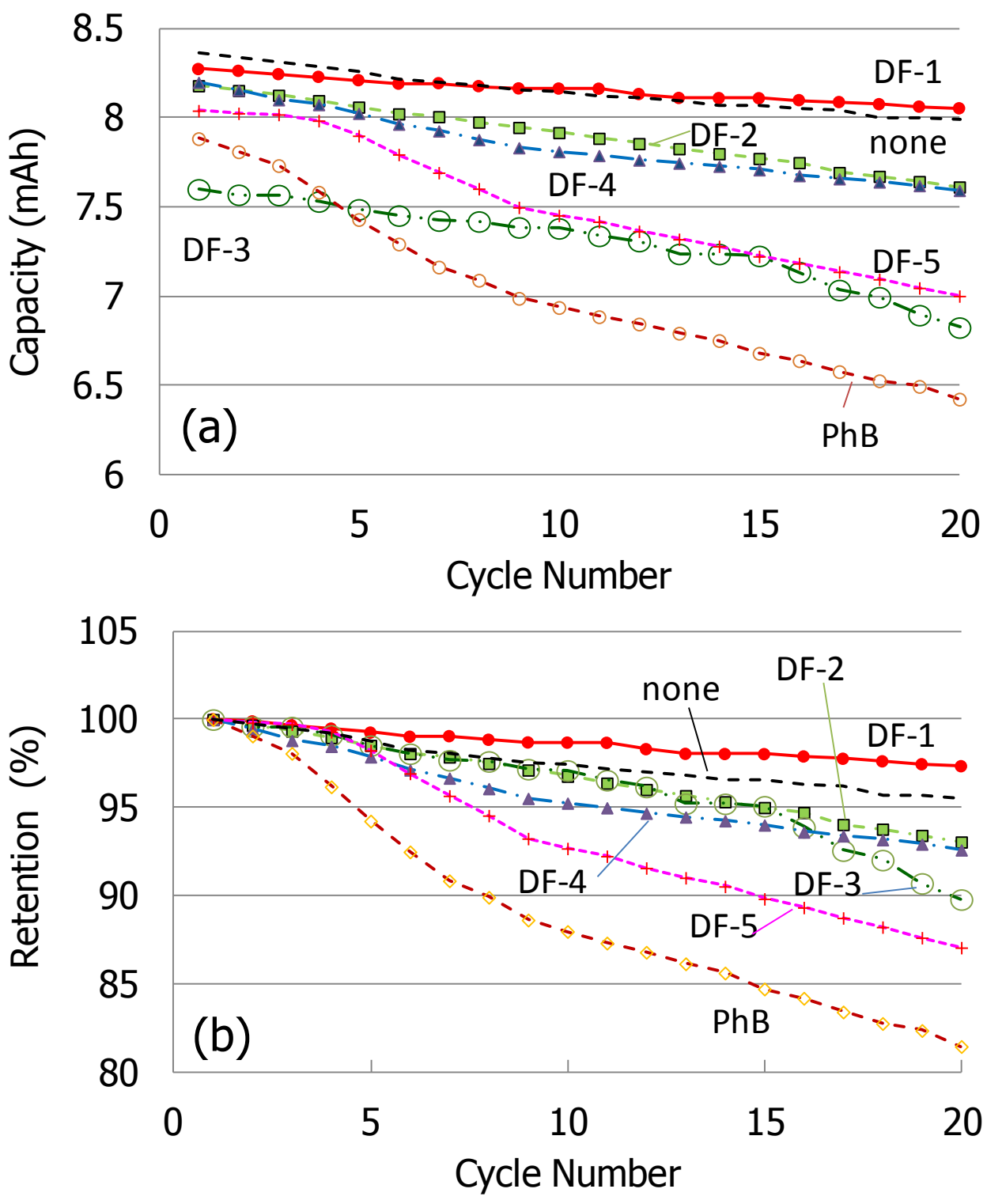
Figure 9. Cycle tests for $\mathrm{LiCoO}_{2} /$ graphite cells cycled between $4.45-3.0 \mathrm{~V}$ : (a) capacity and (b) retention for cells with electrolyte additives of DF-1 (red), DF-2 (yellow-green), DF-3 (green), DF-4 (blue), DF-5 (pink), PhB (brown), and without additive (black).

Figure 10 shows the change in impedance from the first cycle to twentieth cycle at $4.45 \mathrm{~V}$ charge. After the first cycle, the electrolytes with DF-2, $-3,-4,-5$, and PhB have larger impedances than those with DF-1 and without additive. After the twentieth cycle, the impedances of all samples are larger than those for the $4.20 \mathrm{~V}$ charge. Of these additives, the change in impedance for DF-1 is the smallest. As shown in LSV (Figure 2) and CV (Figure 4), DF-2, -3, -4, and -5 have larger oxidation peaks than DF-1, and the oxidation of three additives occurred repeatedly. Therefore, DF-2, $-3,-4$, and -5 presumably form high resistive SEI on the cathode when charged at $4.45 \mathrm{~V}$. On the other hand, DF-1 is less reactive than DF-2, $-3,-4$, and -5 , showing no peaks in CV after the first cycle. These differences in reactivity allow DF-1 to form favorable SEI on the $4.45 \mathrm{~V}$ charging cathode. Thus, DF-1 shows good cycle performance under high charge voltage conditions such as $4.45 \mathrm{~V}$.
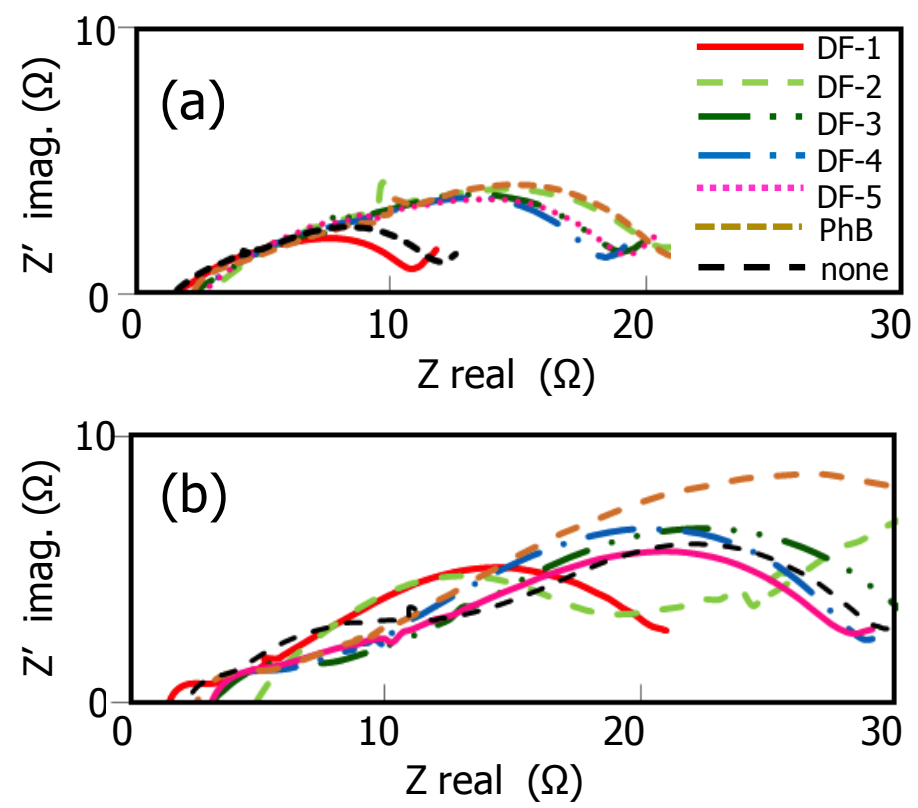

Figure 10. Cole-Cole plots for $\mathrm{LiCoO}_{2} /$ graphite cells cycled between $4.45-3.0 \mathrm{~V}$ at the (a) 1 st and (b) 20th cycles with electrolyte additives of DF-1 (red), DF-2 (yellow-green), DF-3 (green), DF-4 (blue), DF-5 (pink), PhB (brown), and without additive (black). 


\subsection{Surface analysis of the cathode}

Of the difluoroalkenes, DF-1 exhibits interesting cell performance at high charge voltage. It is important to know its mechanism, especially that for SEI formation. Therefore, the SEI formed by DF-1 on the cathode and anode were investigated by XPS and ToF-SIMS, and compared with that of the control electrolyte without additive.

Figure 11 shows XPS spectra of the full cell cathode $\left(\mathrm{LiCoO}_{2}\right)$ at several cell voltages. At $3.1 \mathrm{~V}$, there are no differences in the peaks of $\mathrm{LiF}(685 \mathrm{eV})$, phosphorus, and cobalt between the DF-1 electrolyte and the electrolyte without additive. At 3.7 and $4.4 \mathrm{~V}$, the LiF peak of the DF-1 electrolyte is larger than without additive. At $4.4 \mathrm{~V}$, the cobalt peak of the DF-1 electrolyte is smaller than without additive, which suggests that the cathode with the DF-1 electrolyte is covered by the formed SEI. This DF-1-derived SEI probably covered the activation points of cathode and suppressed the decomposition of electrolyte solvents and LiPF6. Thus, the DF-1 electrolyte has a lower intensity of phosphorus peak than without additive at $4.4 \mathrm{~V}$. In this experiment, carbon is an important element for SEI formation; however, it is difficult to discuss the effect on carbon, because graphite powder and a binder, polyvinylidene fluoride were included in the cathode as carbon sources. To examine the effect on carbon, a sputter-depositing $\mathrm{LiCoO}_{2}(270 \mathrm{~nm}$ thick $)$ electrode was prepared and charged to $4.50 \mathrm{~V}$ vs. Li. 


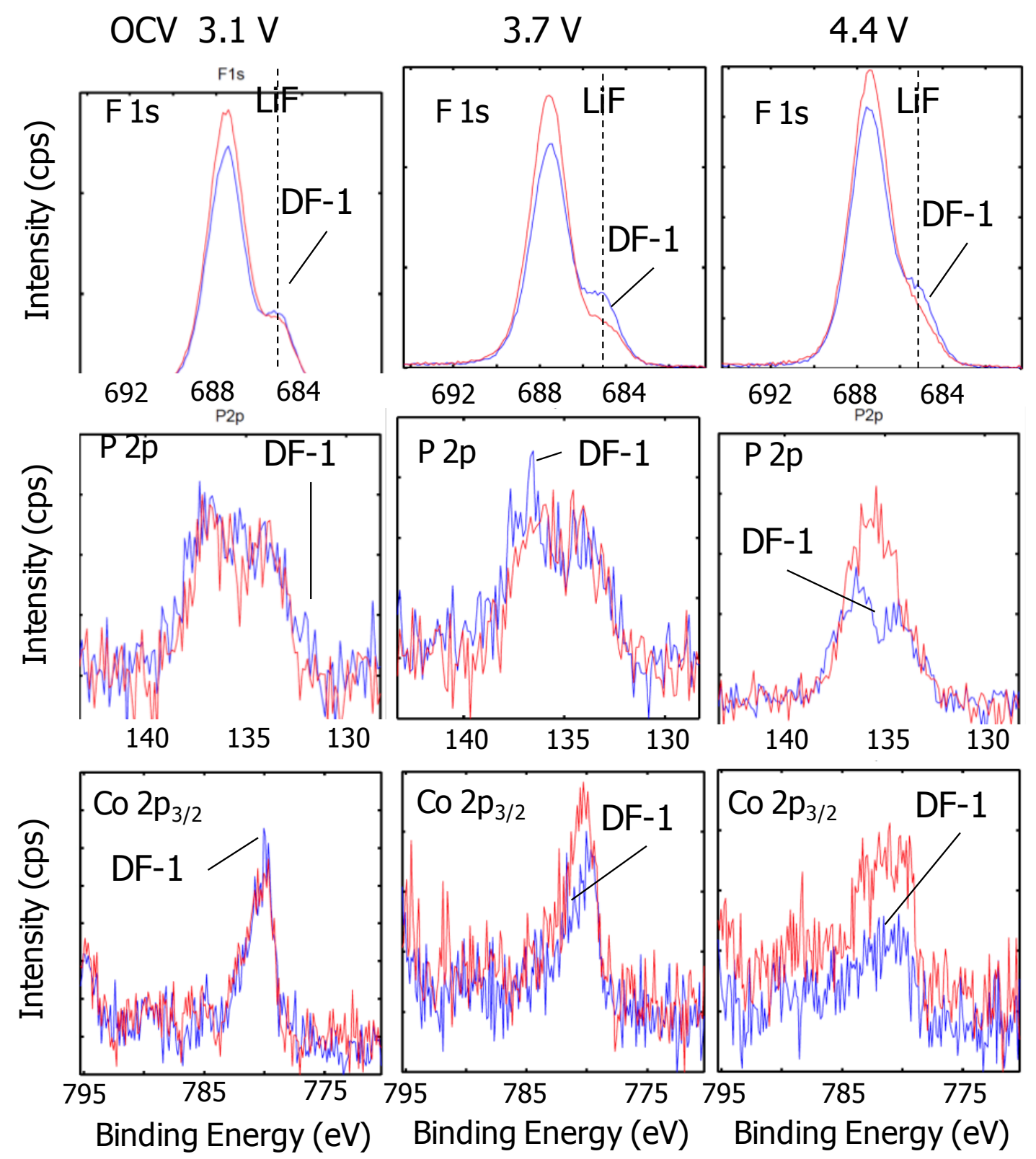

Figure 11. XPS spectra for the cathode electrode of $\mathrm{LiCoO}_{2} /$ graphite cells at $3.1 \mathrm{~V}, 3.7 \mathrm{~V}$, and $4.4 \mathrm{~V}$ (OCV) using electrolytes with DF-1 (blue) and without additives (red). 

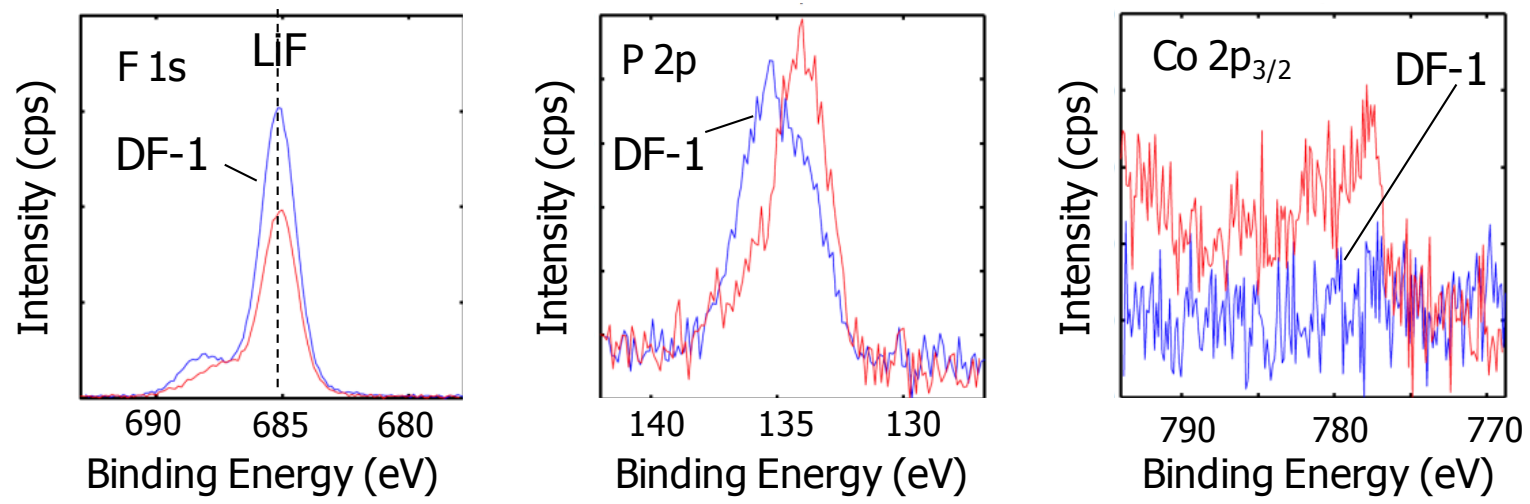

Figure 12. XPS spectra for the sputter-depositing $\mathrm{LiCoO}_{2}$ electrode at $4.4 \mathrm{~V}$ (OCV) using electrolytes with DF-1 (blue) and without additive (red).

Figure 12 shows XPS spectra for the sputter-depositing $\mathrm{LiCoO}_{2}$ cathode charged at $4.4 \mathrm{~V}$ using electrolytes with and without additive. There is a clear difference between the cathodes in the two electrolytes; the cathode in the DF-1 electrolyte has a stronger LiF peak. The cathode in the DF-1 electrolyte has an intense $\mathrm{P}-\mathrm{F}$ bond peak $(136 \mathrm{eV})$, whereas that in the electrolyte without additive shows an intense $\mathrm{PO}_{2} \mathrm{~F}_{2}$ peak $(134 \mathrm{eV})$. The cobalt peak for the DF-1 electrolyte is smaller than that for the electrolyte without additive. These results are almost same as those shown in Figure 11 (at 4.4 V), which suggests that the sputter-depositing $\mathrm{LiCoO}_{2}$ cathode has a reactivity similar to the cathode fabricated with graphite powder and the binder.

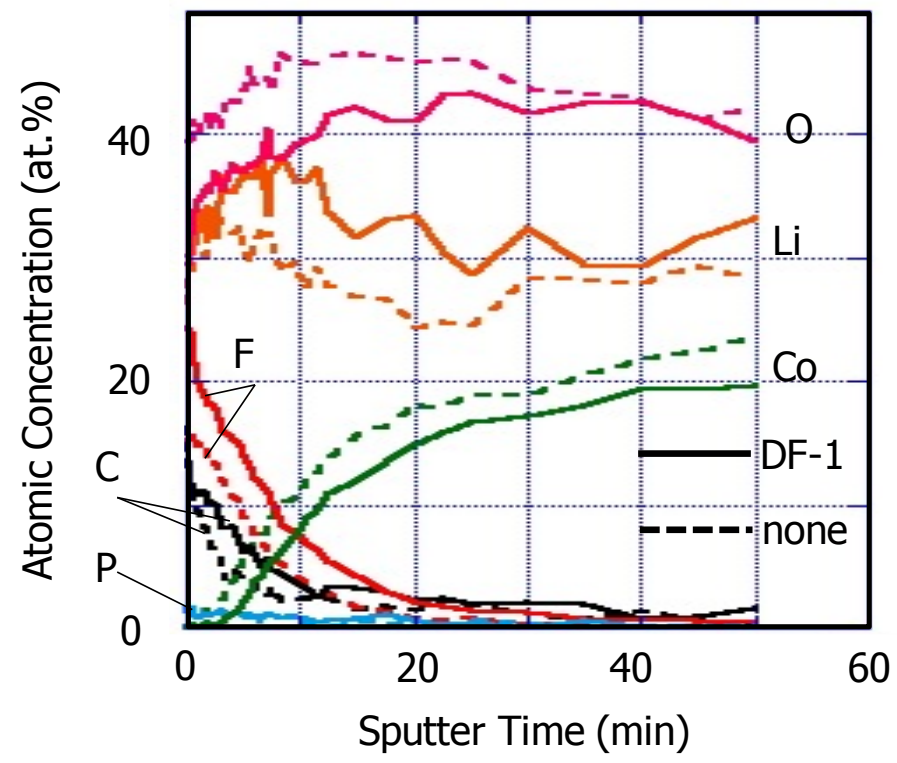

Figure 13. XPS depth profiles for the sputter-depositing $\mathrm{LiCoO}_{2}$ electrode charged at $4.4 \mathrm{~V}$ (OCV) using electrolytes with DF-1 (solid line) and without additive (dotted line). 
To observe the depth profiles of the cathode, XPS measurements were conducted after sputtering the surface of the $\mathrm{LiCoO}_{2}$ electrode charged at $4.4 \mathrm{~V}$ (OCV) using electrolytes with DF-1 and without additive, which is shown in Figure 13. For the SEI on the cathode with the DF-1 electrolyte the concentrations of lithium, carbon, and fluorine are larger, and those of cobalt and oxygen are smaller than those for the electrolyte without additive. These results obtained from XPS measurements suggest that DF-1 forms SEI and protects electrolytes against decomposition.
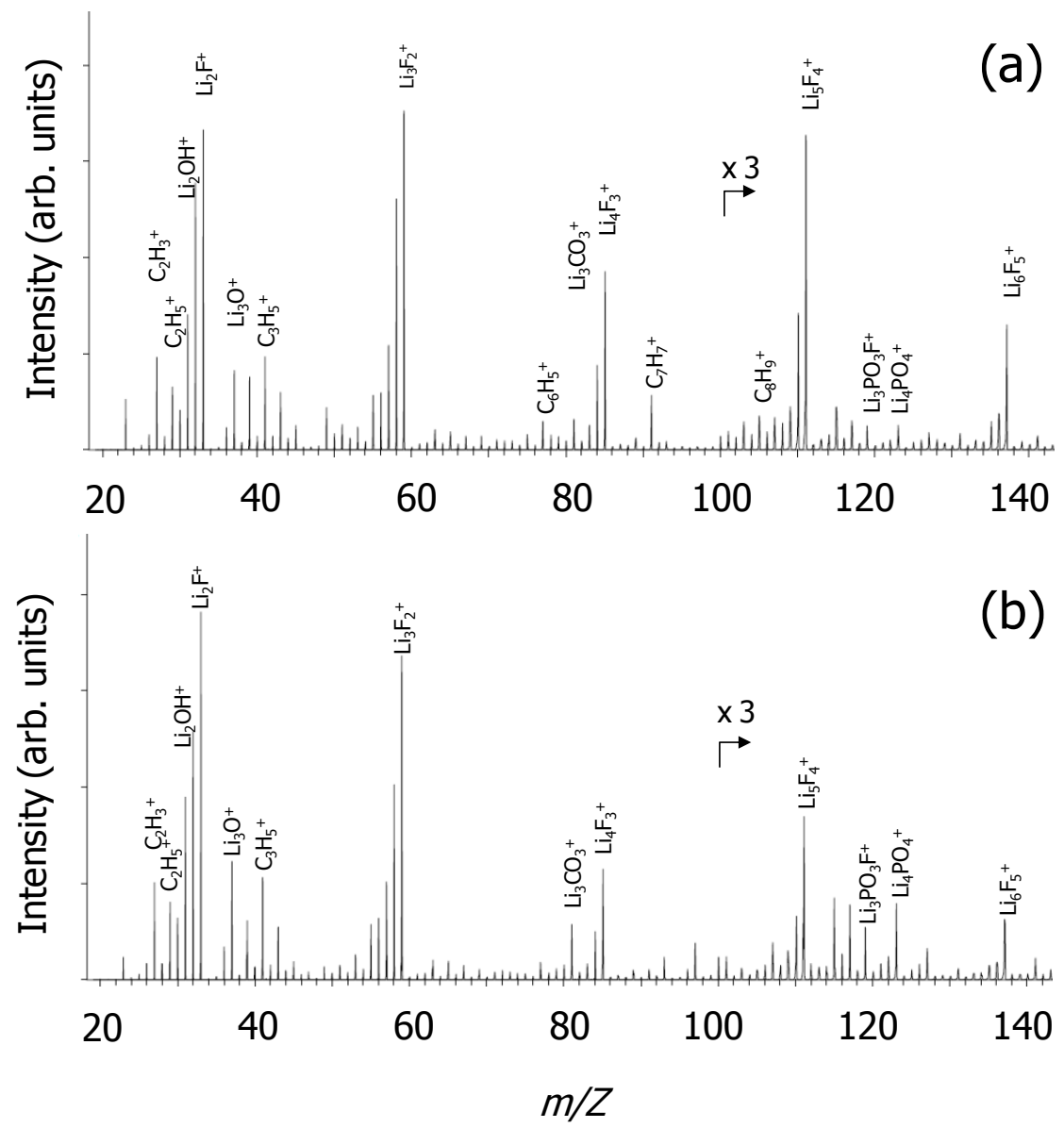

Figure 14. ToF-SIMS surface spectra (positive secondary ion mode) for the sputter-depositing $\mathrm{LiCoO}_{2}$ electrode charged at $4.4 \mathrm{~V}$ (OCV) using electrolytes (a) with DF-1 and (b) without additive. 

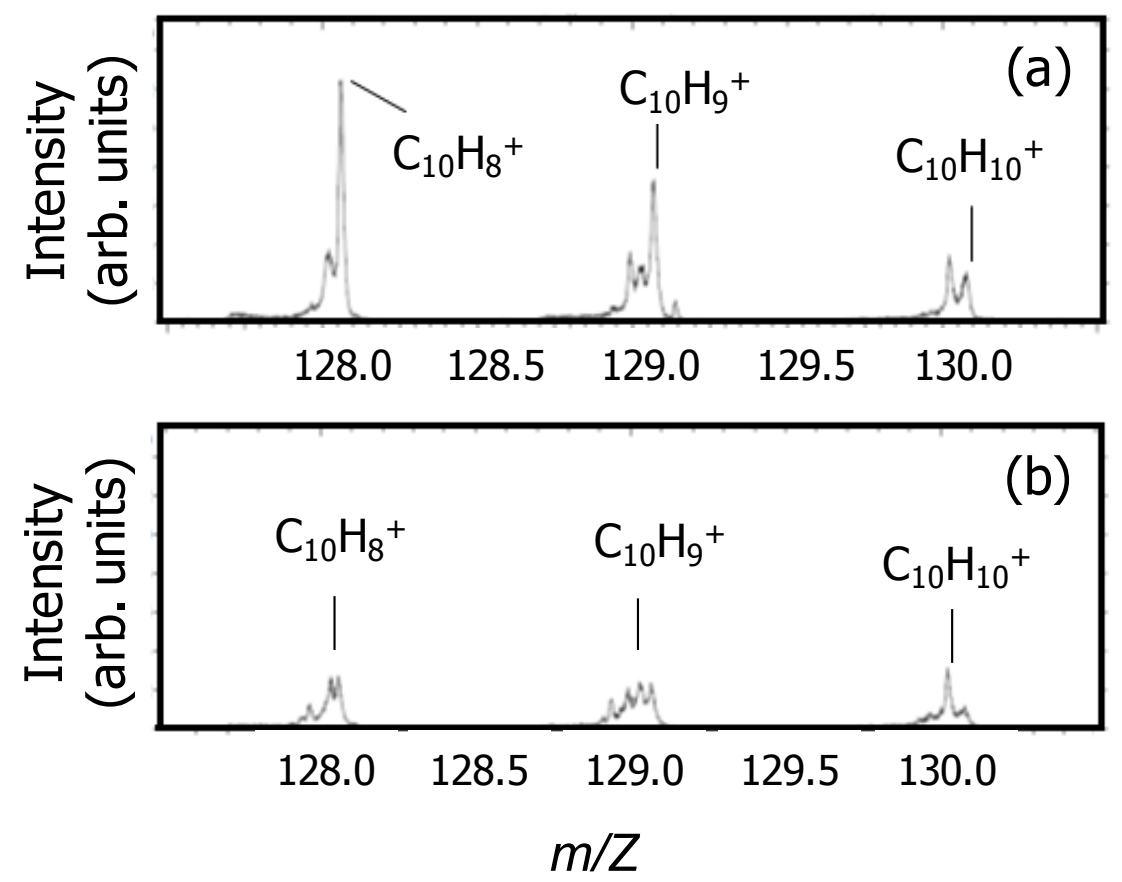

Figure 15. Enlarged part of Figure 14: (a) with DF-1 and (b) without additive.

Figures 14 and 15 show the surface spectra of ToF-SIMS positive ion mode measurements using the sputter-depositing $\mathrm{LiCoO}_{2}$ thin film electrodes after the first charge. $\mathrm{Li}_{\mathrm{n}+1} \mathrm{~F}_{\mathrm{n}}{ }^{+}(\mathrm{n}=1-5)$ peaks, derived from lithium fluoride, are observed at both surfaces, and the electrode surface of the DF-1 electrolyte has a larger $\mathrm{Lin}_{n+1} \mathrm{~F}_{\mathrm{n}}{ }^{+}$peaks than that of the electrolyte without additive.

In addition, peaks derived from hydrocarbons, such as $\mathrm{C}_{10} \mathrm{H}_{10}+\mathrm{C}_{10} \mathrm{H}_{9}+\mathrm{C}_{10} \mathrm{H}_{8}+\mathrm{C}_{9} \mathrm{H}_{9}{ }^{+}, \mathrm{C}_{9} \mathrm{H}_{8}{ }^{+}$, $\mathrm{C}_{8} \mathrm{H}_{9}{ }^{+}, \mathrm{C}_{8} \mathrm{H}_{8}{ }^{+}, \mathrm{C}_{8} \mathrm{H}_{7}{ }^{+}, \mathrm{C}_{7} \mathrm{H}_{7}{ }^{+}$, and $\mathrm{C}_{6} \mathrm{H}_{5}{ }^{+}$, are evident in the surface spectrum of the cathode with the DF-1 electrolyte [Figure 14(a) and Figure 15(a)], which suggests that these peaks are mainly derived from DF-1. There are no fluorinated peaks for these C8-C10 fragments, indicating that DF-1 is defluorinated, which is also confirmed by Figure 13: the concentration of fluorine for the electrolyte with DF-1 is larger than without additive.

Ichikawa et al. reported that a limited number of electrophiles, for example magic acid $\left(\mathrm{FSO}_{3} \mathrm{H} \cdot \mathrm{SbF}_{5}\right)$ can activate 1,1-difluoroalkenes, and that difluoroalkenes bearing an aryl group undergo a Friedel-Crafts-type cyclization accompanied by elimination of hydrogen fluoride [12]. Because the $4.45 \mathrm{~V}$ charged cathode has a very high electrophilic atmosphere, similar reactions seem to occur on the cathode surface to release fluoride ions. 


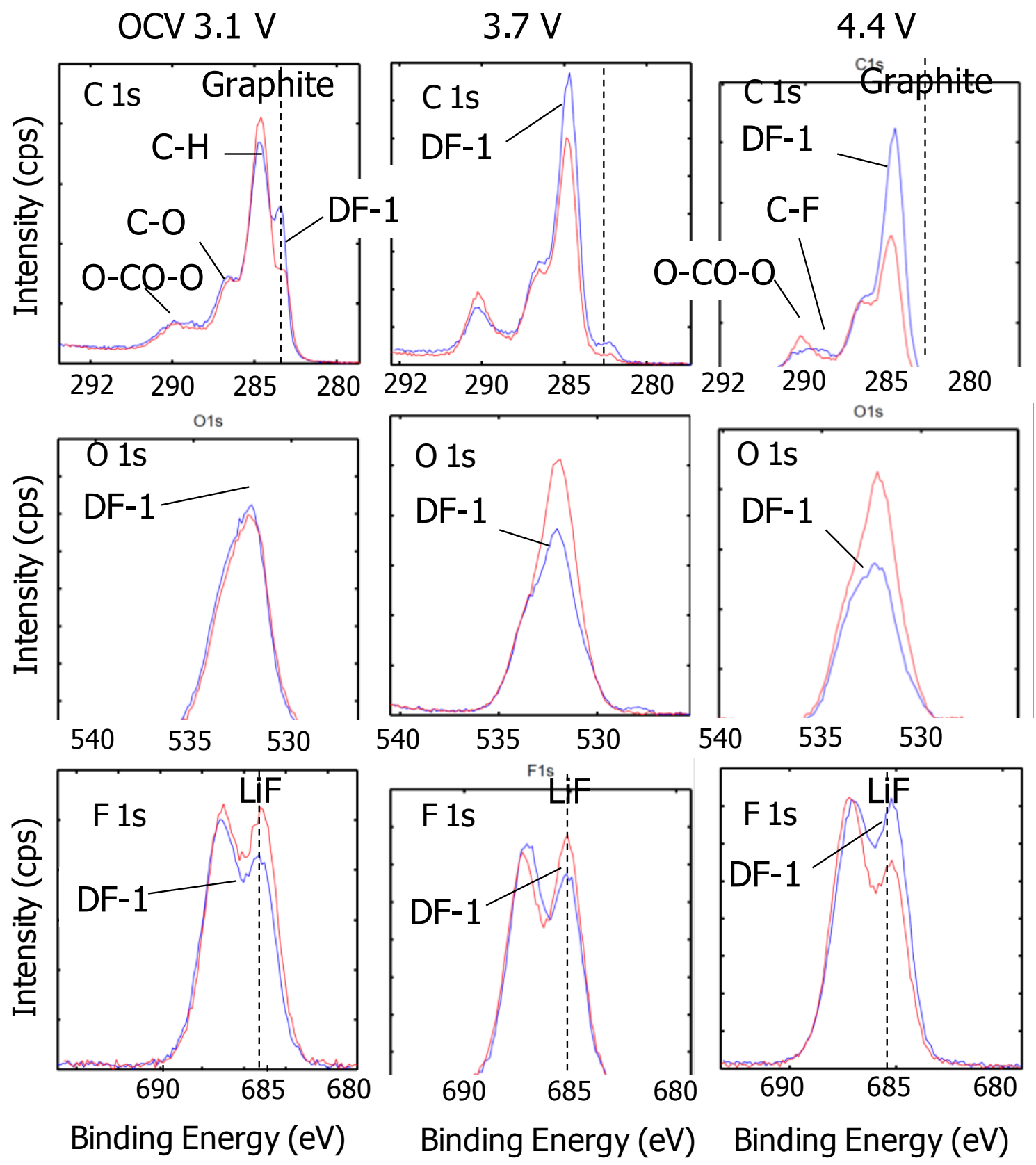

Figure 16. XPS spectra for graphite anode at $3.1 \mathrm{~V}, 3.7 \mathrm{~V}, 4.4 \mathrm{~V}$ (OCV) using electrolytes with DF-1 (blue) and without additive (red).

Surface analysis was also conducted on the anode. Figure 16 shows XPS spectra of the graphite anode at several cell voltages. Carbon peaks at 290, 286, 285, and $283 \mathrm{eV}$ indicate $\mathrm{O}-\mathrm{CO}-\mathrm{O}, \mathrm{C}-\mathrm{O}$, and $\mathrm{C}-\mathrm{H}$ from the binder, and $\mathrm{C}-\mathrm{C}$ from graphite, respectively. At $3.1 \mathrm{~V}$, the carbon peaks from the DF-1 electrolyte and without additive are different. The carbon peak due to graphite appears clearly in the 
anode with the DF-1 electrolyte, whereas that for the electrolyte without additive is obscured by electrolyte decomposition materials. The oxygen peaks for both electrolytes are same. The LiF peak for the electrolyte without additive is larger than that for the DF-1 electrolyte. At $3.7 \mathrm{~V}$, the anode with the DF-1 electrolyte has a smaller oxygen peak than without additive. At $4.4 \mathrm{~V}$, a new carbon peak appears around $289 \mathrm{eV}$, which can be attributed to CHF unit (ca. $289 \mathrm{eV}$ ) [17]. Note that PVDF or PTFE were not used in the fabrication of this anode. Another possibility for this peak is carboxylic carbon (ca. $290 \mathrm{eV}$ ); however, carboxylic acids are hardly produced from DF-1 under these non-aqueous conditions, and the oxygen peak observed at $4.4 \mathrm{~V}$ is smaller than at other voltages shown in Figure 16. Therefore, it is considered that the new carbon peak is due to the presence of fluoromethylene (CHF) compounds. The intensity of the $\mathrm{C}-\mathrm{H}$ peak $(285 \mathrm{eV})$ with the DF-1 electrolyte increases according to the charge level. The LiF peak $(685 \mathrm{eV})$ with the DF-1 electrolytes is smaller than without additive at 3.1 and $3.7 \mathrm{~V}$, while being larger than without additive at $4.4 \mathrm{~V}$.

These results suggest that the SEI on the anode is favorably formed by DF-1 at a higher charging state $(4.4 \mathrm{~V})$, and that the SEI includes LiF and hydrofluorocarbons. It should be noted that DF-1 can form SEI not only on the high charged cathode but also on the anode, which results in a marked improvement in cycle performance.

\section{Conclusion}

Unique difluoroalkenes DF-1 to -5 were investigated as a new type of electrolyte additives for lithium ion batteries to induce SEI formation. Interestingly, DF-1 provides good cycle performance under high charge voltage condition. On the other hand, the other difluoroalkenes, DF-2, $-3,-4$, and -5 adversely affect cycle performance, because they have high reactivities with cathode over $4.20 \mathrm{~V}$ charge to form high impedance SEI. DF-1 is less reactive than the others and the SEI formation might cease during the first cycle. Therefore, DF-1 forms favorable SEI at $4.45 \mathrm{~V}$ charge. The SEIs formed on the cathode and anode formed with the DF-1 electrolyte were investigated using XPS and ToF-SIMS. As we expected, the cathode surface has a LiF-rich layer and unsaturated hydrocarbons derived from DF-1. Moreover, the anode also has LiF-rich layer, which probably includes fluoromethylene (CHF) 
compounds. Because of the SEI on the $4.45 \mathrm{~V}$ charged cathode and anode, DF-1 particularly improves cycle performance. This study provides the guidelines for molecular design aimed at developing new electrolyte additives for high capacity lithium ion batteries.

\section{References}

[1] Y. Idota, T. Kubota, A. Matsufuji, Y. Maekawa, T. Miyasaka, Science 276 (1997) 1395.

[2] H. Inoue, Proceedings IMLB, 2006, 0228.

[3] H. Ota, Y. Satake, A. Inoue, S. Yamaguchi, J. Electrochem. Soc. 151 (2004) A1659.

[4] G.H. Wrodnigg, J.O. Besenhard, M. Winter, J. Electrochem. Soc. 146 (1999) A470.

[5] M. Ihara, B.T. Hang, K. Sato, M. Egashira, S. Okada, J. Yamaki, J. Electrochem. Soc. 150 (2003) 1476.

[6] R. Mogi, M. Inaba, S. Jeong, Y. Iriyama, T. Abe, Z. Ogumi, J. Electrochem. Soc. 149 (2002) A1578.

[7] H. Nakai, T. Kubota, A. Kita, A. Kawashima, J. Electrochem. Soc. 158 (2011) A798.

[8] A. von Cresce, K. Xu, J. Electrochem. Soc. 158 (2011) A337

[9] Y. Watanabe, S. Kinoshita, S. Wada, K. Hoshino, H. Morimoto, S. Tobishima, J. Power Sources 179 (2008) 770

[10] J. Li, W. Yao, Y. S. Meng, Y. Yang, J. Phys. Chem. 112 (2008) 12550.

[11] L. Yang, B.L. Lucht, Electrochem and Solid-State Lett., 12 (2009) 229.

[12] J. Ichikawa, H. Jyono, T. Kudo, M. Fujiwara, M. Yokota, Synthesis 1 (2005) 39.

[13] M. Yokota, D. Fujita, J. Ichikawa, Org. Lett. 9 (2007) 4639.

[14] W. A. Vinson, K. S. Prickett, B. Spahic, P. R. Ortiz de Montellano, J. Org. Chem. 48 (1983) 4661.

[15] K. Shima, M. Ue, J. Yamaki, Electrochemistry, 71 (2003) 1231.

[16] R. Fong, U. von Sacken, J. R. Dahn, J. Electrochem. Soc. 137 (1990) 2009.

[17] J. F. Moulder, W. F. Stickle, P. E. Sobol, K. D. Bomben in: J. Chastin, R. C. King (Eds.), Handbook of X-ray Photoelectron Spectroscopy, Physical Electronics Inc., Eden Prairie, MN, 1995, pp. 40-41. 